\title{
BEST BEFORE? \\ ADVANCED GEOMATICS FOR PRESERVATION AND PRESERVATION OF ADVANCED GEOMATICS.
}

\author{
Sofia Celli ${ }^{1}$, Davide Del Curto ${ }^{2}$ \\ ${ }^{1}$ Università di Parma, Department of Engineering and Architecture \\ ${ }^{2}$ Politecnico di Milano, Laboratory of Analysis and Building Diagnostic, Department of Architecture and Urban Studies
}

KEYWORDS: preservation, traditional survey techniques, advanced geomatics, obsolescence

\begin{abstract}
:
This discussion paper deals with the task of preserving past geometrical surveys and keeping them in use. The continuous advancement in technology caused a quick ageing of both survey techniques and their outcomes. This may result into a predetermined expiration date after which they risk losing their quality and usefulness (hence the title «Best Before»). Facing this risk, this paper focuses on the unceasing relevance of past surveys both as a legacy in the history of technique and as a fundamental source of information on heritage buildings, and thus a support to the preservation activity. The present paper offers an overview of the most recent attempts of preserving and keeping in use the paper surveys of the past.
\end{abstract}

\section{INTRODUCTION}

The research on geomatics in the field of heritage preservation has been focused on operative aspects for the last two decades. The rapid evolution of the instrumentation has brought us to new and unexpected outcomes. Nevertheless, this upgrade has been so quick that nowadays we risk considering geometric surveys to be disposable goods.

The relatively recent large-scale diffusion of computers and design software has left behind a huge legacy of paper format documents and drawings that risk being considered obsolete, as the potential of the newest geomatic tools often pushes the professionals to conduct surveys from scratch. Nevertheless, when it comes to investigating historic heritage it is common to come across pre-existing surveys, conducted over the years using traditional techniques. These documents are a source of valuable information documenting the state of conservation of each building and site over time. They also represent a legacy in the history of technique, topography and representation.

This paper reflects on whether it is worth acting to ensure the conservation-in-use of those surveys and how. The question of how to deal with paper format documents and drawings of the past also refers to the worldwide issue of digitalization, that is a driver for jobs and growth and a pillar in the field of research. We may thus wonder what the future holds for all those drawings that are no longer considered functional or updated with respect to the newest software.

\section{TRADITION vs EVOLUTION}

Andrea Palladio, in the preface of his third Book of Architecture asserted that $"[. .$.$] much more is learnt in a little time from good$ Examples, or Originals by measuring of them and by seeing entire Edifices with all their parts describ'd on a little piece of
Paper; than can in a long time be learnt from words, by which the Reader becomes able only in Idea, and not without some difficulty, to attain to a firm and certain knowledge of what he reads, and to bring it afterwards into practice with great fatigue» (Leoni, 1742).

Since time immemorial, the art of construction has been apprehended by architects and conservators through the execution of geometric surveys. By observing, measuring and drawing buildings and sites, they acquired knowledge of proportions, materials and construction techniques and this happened primarily thanks to direct and prolonged contact with the buildings themselves.

Five centuries after Palladio, advanced geomatic technologies have opened a new realm of (at the time) unconceivable possibilities. Along the line of evolution of geomatic techniques, pre-existing surveys still bear information about previous stages of the stratified construction of a historic building or site. Each drawing embodies an historic threshold that related to the real object and to archival documents allows us to backdate modifying interventions, to identify structural behavior, as well as to clarify origins.

"...the geometric interpretation of architecture focuses on both the simple "shapes" that guarantee the regularity of the drawing, and the deformations and transgressions that deny that same regularity, raising questions regarding the "intentional" or "accidental" motives that could have caused them" (1). (Torsello, 1988) The great potential of geometric survey hence lies in its ability to raise doubts and questions that, leading to further analysis, results in an overall better knowledge of the building (Musso, 2017a). Therefore, surveys are a fundamental resource to investigate the origin of the architectural object, searching in current geometry the ancient shapes and equilibrium from which the art of construction used to derive Vitruvio's firmitas. Since Giovanni Poleni and the Memorie istoriche della gran cupola del tempio vaticano, geometric survey has been at

(1) Quote translated by the authors. 
the basis of the comprehension of the structural behavior of a building. The deformed shape of the original configuration, which is often clearly visible in survey's graphic restitutions, represent the earliest useful hint to interpret existing structural mechanisms, highlighting the possible need to plan a strengthening intervention. A significant lowering of the brick dome of Santa Maria del Quartiere church in Parma was detected by means of laser scanning in 2009. It is a typical symptom of the most classic collapse mechanism of this type of structures. In this particular case, the study over the original proportions was not only helpful in order to confirm the interpretation of such a specific structural behavior, but it was also fundamental to understand to whom the project of the church was to be attributed. In fact, a careful metrology investigation confirmed the authorship of the renowned architect Giovan Battista Aleotti from Ferrara (Ghiretti et al., 2009). More in general, since the final goal of both today's and yesterday's surveys is to deep our knowledge about a building or a site, it is worth comparing the results of geometrical surveys conducted in the past and in the present. We may thus raise some epistemological questions in terms of accuracy, and in terms of effectiveness to the specific field of heritage conservation.

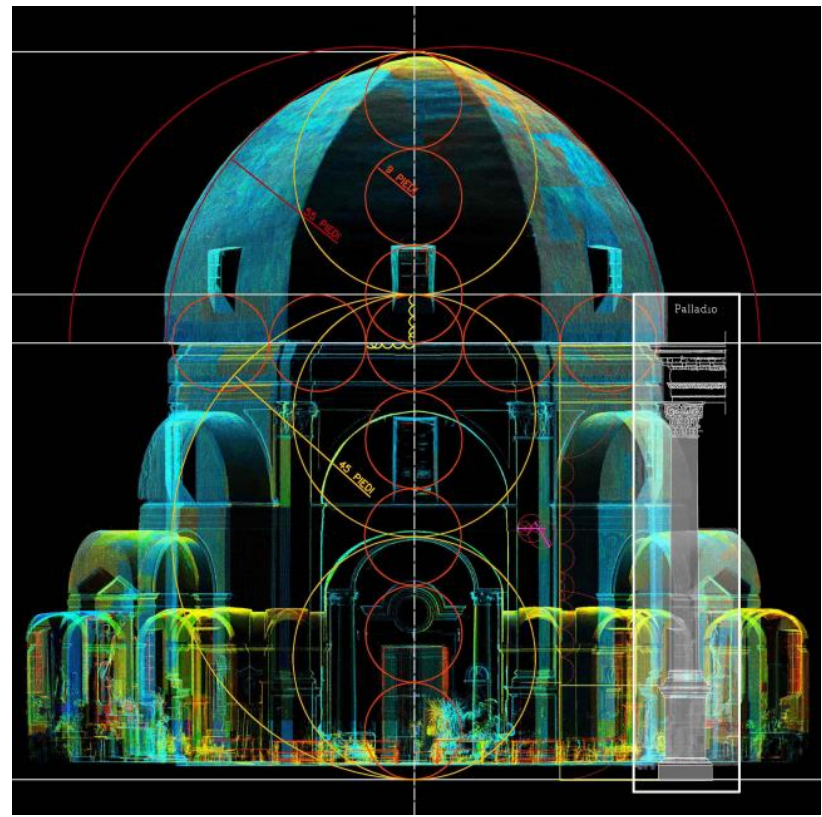

Figure 1. Graphic analysis and metrology study of the Santa Maria del Quartiere church in Parma. (Ghiretti et al., 2009)

\subsection{Time}

From an operative point of view, digital technologies have noticeably shortened the lapse of time an operator is required to physically spend on-site, in favor of the time he/she must spend in front of a display, thus interrupting the continuity of gestures that has bound together the original builder and the architectrestorer for centuries. This shift had significant repercussions on the final outcome both in terms of knowledge of the building and of the accuracy of produced drawings. With traditional techniques, the time spent on-site was nearly the same as the time spent for the graphical restitution of data. In fact, the measurement campaign required major planning. The operator needed to identify the most significant points of the building from

(2) By definition: «The term Bauaufnahme is understood as the method of exact recording of three-dimensional form or structure the beginning, in order to focus on the elaboration of the drawings that were considered to be the most useful to the architect in charge of the restoration project. This implied a continuous and direct contact with the building and the subsequent opportunity and time to get to know the architecture, identifying its peculiarities and its most significant features.

Nowadays, thanks to the spreading of advanced survey techniques, the situation has changed, as the time related to the actual measurement of the object has been reduced to a minimum. If on one side new technologies have significantly shortened the on-site operations, leaving them the role of a pure recording of data, on the other it has postponed off-site the critical discernment phase. Hence, the real knowledge of the building does not belong any more to a prolonged on-site contact, but to the subsequent interpretation of the data collected on-site (Docci et al., 2001a).

\subsection{Skills}

Another operative difference between traditional and advanced methods concerns the technical expertise required to manage the survey campaign and, even more, the following phase of two and three-dimensional restitution of data.

«The conversion of the picture (the object of surveyance) into a facsimile (the drawing to be made) is inevitably coupled with a loss of information. For the researcher, this means being forced to interpret the findings or data in order to make his plan - in other words, making a selection from the available information. While photos provide a fairly true record of the visible surface, the graphic representation of a Bauaufnahmezeichnung (2) is dependent on the goal of the researcher and his ability and knowledge» (Schmidt, 2002). In this regard, if handwritten sketches and measurement were accessible nearly to anyone, the managing of a point cloud is delegated to few skilled operators. Their skill consists in extracting a continuous 2D drawing from a complex discrete 3D model. When operating in the field of conservation, this distance is highly relevant, as very often the restorers themselves do not have the expertise to deal with the point clouds, and they are hence denied access to the original data. On the upside, 3D laser scanner models store an enormous amount of data from which we can deduct even information that we did not know we would need at the time of the survey. This results in a time saving because it allows to clear uncertainties without necessarily planning new on-site inspections. As an instance, this could be the case for deformations: having the possibility to navigate a high precision virtual model allows us to identify the most deformed points as well as to quantify their extension, hence providing all the data required for a preliminary assessment of the stability of the building.

\subsection{Scale}

The issue of technical expertise has a strong connection to the scale of representation. The scale of the final drawings had traditionally to be defined before conducting a survey. The operator could therefore perform the measurement on site with a clear idea of the level of detail to be transferred to the final drawing. Advanced survey techniques grant the possibility to represent the whole object instead of specific predetermined drawings and thus allowing to avoid the need to define the scale of representation in advance. The choice of the scale of representation is delayed to a second phase. The model can then be queried many times and can thus provide countless views to be elaborated at different scales. However, it is to be noted that

into two-dimensional drawings based on exact measurements» (Schmidt, 2002) 
the initial setting of the laser scan resolution has implications on the outcome of a survey and it is therefore still useful to have a clear idea of the final objective, in order to correctly calibrate the operations on site (Senatore, 2011).

\subsection{Matter}

Even though advanced survey technologies have brought a significant improvement in terms of precision, speed, and amount of collected data, there are aspects of traditional techniques that still seem to be hard to automate entirely. A consistent part of the restoration process deals with matter and its alterations, which are often hard to be evaluated from a distance. Visual inspection, as well as tactile perception of matter are essential and still seem to be hardly replaceable by means of existing devices. Moreover, most of diagnostic investigations carried out on building materials rely on the non-invasive digital technique of multispectral imaging, e.g. thermal imagers, laser scanner etc. This technology finds applications in many different fields and it basically results in the creation of a virtual model that regulates its relationship with reality through specific conventions, contributing to increase the distance between the operator and the physical object. This progressive estrangement puts us at risk of slowly losing the ability of critically interpret the reality we experience, impairing the unfolding of the original process that starting from direct observation led to thorough knowledge of the architectural object. A collateral benefit obtained by spending time on-site is the acquisition of awareness of the context on which we are going to operate. This is extremely important as it gives us the possibility to observe situations and behaviors that could have an impact (either positive or negative) on the conservation of the building itself, e.g. particular climatic conditions or unsuitable conducts of the users.

\subsection{Accuracy and cogency}

Another aspect worth considering when comparing traditional and advanced survey techniques is accuracy. As widely noted, the field of restoration has borrowed several techniques from other sciences, adapting them to its specific requirements. Since the parallel between physician and restorer is quite common, many investigations technologies derive from the world of medicine. As a matter of fact, basing on symptoms, architects try to identify the hidden causes that originated the problem, hence finding a cure that is not a mere palliative acting on the evidence, but that eradicates its latent origin. When drawing the conclusions of PRIN 2007, Mario Docci highlighted the need to further develop the software used to manage the threedimensional laser scanner, in order to grant more flexibility in the setting of the scan. In fact, laser scanning requires to specify the density of the grid of points to map. Once defined, this value remains fixed. This may be a problem when working on historic architecture, since the complexity of the elements to survey may significantly vary from plain surfaces to elaborate decorations. Docci suggested to increase the flexibility of laser scanner technology by augmenting the amount of data to memorize on the basis of the morphology of the buildings (Docci, 2011). Although in the past decade this technology has been largely improved, we wonder how to further develop an instrument not primarily designed with the purpose of built heritage analysis and therefore how to take it to a higher level of cogency in relation to the final objective of preservation.

At the end of this comparison, despite the few mentioned risks, we can assert that the continuous evolution of investigative technologies is undoubtedly an asset. By pushing us towards increasingly innovative horizons, it allows new information to emerge, suggesting brand new interpretations, even for those monuments that we believed to know in depth. Even so, we may wonder, at least theoretically, whether advanced survey techniques will grant us the same level of awareness of traditional ones and therefore, at the risk of appearing nostalgic, whether advanced geomatics are always the fittest tool to investigate architectural heritage.

\section{GEOMETRIC SURVEYS AS CHRONICLES OF BUILT ENVIRONMENT}

Paper surveys produced over time represent the main investigative tool to retrace the constructive history of an heritage building. The comparison between different historical thresholds allows to identify and to date the transformations that modified the building and gave it its current appearance. This does not merely regard formal aspects; once more, past modifications of the structure can help to recognize the causes of today's problems and hence to chose the fittest solutions. In order to gain a complete understanding of the traces due to past transformations, it is necessary to integrate data deduced from drawings with information retrieved from archival and bibliographic sources and with the direct inspection of the building itself. The complementarity of text documents and drawing still is unavoidable to our days, since each architectural proposal finds a counterpart in a written report.

The awareness of the importance of pre-existing surveys as a goldmine of information to heritage conservation is nowadays largely acknowledged, but also historically, drawings have often been preserved and kept-in-use as instruments to ease the conservation and management of buildings and sites. Religious archives accompanied the growth of cathedrals all over Europe, by recording a number of information on both the conception and the state of repair of structures and domes. As an instance, the archive of the Opera di Santa Maria del Fiore, stores an enormous amount of documents concerning the constructive history of Florence cathedral, from the time of its design up to current days. The collection of all these data has led to a better planning of the maintenance interventions throughout the years. They hence testify how the behaviour of the maintainers has evolved in time, along with the history of restoration in Europe. Firstly, as the theories of restoration started to bloom in the 19th century, the main purpose was to keep the building functioning. For the same reason, most of the documentation concerning the maintenance of the cathedral were stored to keep better track of expenses and were therefore strictly connected to the financial management of the complex. Secondly, during the early period of the Opera, the typical tools to plan interventions were not drawings, but brick or wooden models, that were appreciated as a pre-digital and effective form of representation. Some of these models are nowadays preserved within the Opera Museum in Florence.

It is to be noted that such big and complex constructions always required constant monitoring and upkeep. This is the reason why interventions were not always carried out when there was an actual problem, as some preventive actions were planned and periodically executed. The reports written by the chief architect of the Opera portray the state of conservation of the complex year by year, and propose a solution for each specific problem. The possibility to access such a register of previous activities, provided contemporary professionals with useful suggestions in order to identify the most suitable responses to present issues, as they derive from the past. Or, vice versa, warned them about the unsuccessful turn out of certain kinds of interventions. Finally, it is interesting to point out how, in the case of the cracks of Brunelleschi's dome, the documentation is a primitive form of monitoring. In fact, periodical observation about the conditions 
of the cracks were carefully noted in the reports, granting their control over time (Guasti, 1857) (3).

Both historically and in recent years, pre-existing surveys have often proved essential to the conservation of historical memory. This is the case for the San Marco's bell tower, which disastrously collapsed in 1902 and was reconstructed in the following years on a design by Luca Beltrami. The new bell tower was built as it was and where it was, according to the principles of scientific restoration, thus basing on graphic and iconographic documentation describing the ancient monument. Similar interventions were carried out in many Italian towns during the second post war period. Several thoughtful superintendents, foreseeing the destruction brought by bombings in 1943-45, rushed to survey and document the most significant historical monuments, bridges and infrastructures as they were some of the most likely targets to be destroyed. It is worth recalling the case of the bridges in Verona, where superintendent Piero Gazzola gathered a few colleagues and started an actual survey campaign, trying to collect as many information as possible. This way, in case of destruction, the community would have at least had the memory of the past configuration. The longsightedness of this architect allowed to reconstruct the demolished bridges in their original shape, therefore helping in overtaking the memory of the war damages caused.

The issue of the destruction of memory due to natural and war damages has been relevant along the 20th century and it still represent a problem in many critical areas worldwide. A number of monuments have been intentionally erased, without leaving any trace behind. To restore at least some of the lost pieces of memory, the collection of all sorts of historical data, along with the development of digital technologies has allowed to recreate virtual representations of several buildings that no longer exist. The case of the two monumental Bamiyan Buddhas (Afghanistan) aroused international interest. Since their destruction, operated by Taliban forces in 2001, a debate on whether to reconstruct them has started. Although no final decision has yet been taken, some actions aimed at supporting a possible reconstruction have already been carried out. With specific focus on the "Great Buddha", a group of scholars at ETH have completed an image-based 3D reconstruction obtained by using different sets of images e.g. tourist-type, web-source and metric images, and several algorithms (Grün et al., 2004a). Later on, in 2015, two Chinese filmmakers employed 3D light projections to cast the hologram of the Great Buddha into its original niche, proposing an alternative and temporary way to restore at least the image on-site and at real scale. A similar initiative has been launched to virtually reconstruct the ancient city of Palmyra (Syria), greatly damaged by recent conflicts. The project does not only aim at digitally reconstructing each of the lost buildings, while it has the higher ambition of establishing a comprehensive virtual representation of the whole Palmyra. Of course, this has been possible due to the immediate availability of a large volume of information of both textual and graphic nature (Denker, 2017a). An online platform was built to support this project; \#NewPalmyra is a website created with the purpose of collecting data and expertise from international partners, as well as of publicly sharing the outcomes of the work. So far it has been possible to develop three-dimensional models of five demolished buildings. These recent experiences confirm the importance of encouraging the preventive safeguard of endangered built heritage, conducting systematic surveys to be used as a documental source for either conservation activities or even possible reconstructions.

(3) Information concerning the Opera of Santa Maria del Fiore has been retrieved both from Cesare Guasti's edited collection of
On a larger scale, cartography historically allowed public bodies and private owners to control the boundaries of their territories and to establish tax systems. The drawings and engravings of the Theatrum Statuum Sabaudiae Ducis, published in 1682 at the behest of Carlo Emanuele II were mainly intended as an instrument to advertise the greatness of the Savoy state within the European courts. Nevertheless, this document was also an important planning tool. In fact, the drawings do not portray the real aspect but an embellished version of the duchy, displaying an operative intent towards an improved future planning. Moreover, the studies conducted in preparation of this document started a process of knowledge that, in the Eighteenth century, led to the drafting of the first land register and to the following establishment of taxation fees (Marabotto, 2010).

This was not an isolated case as, in the same century, systematic surveys of the territory were also carried out in other Italian regions. At the time, cartography was the most useful instrument to govern a state. By displaying the administrative borders, the road network (therefore the circulation of goods and travelers), the defense system, the hydrological features and so on, it gave the ruling class a clear picture of the criticalities and the potentialities of the territory, influencing further developments (Archivio di Stato di Milano, 1984).

However, the relevance of paper format surveys is not merely connected to their informative feature. As products of specific times in history, they are physical evidence of survey techniques of the past and therefore they represent a legacy in the history of technology. As such, they are worth preserving as a heritage themselves, beyond their key role in architectural or archeological preservation. In this regard, architectural surveys can easily be included in the list of "cultural goods" defined by the Italian code of cultural heritage and landscape (Codice dei beni culturali e del paesaggio, 2004) as any object representing a significant testimony of human civilization. Likewise, past surveys have a testimonial value in the history of representation. Drawing codes have developed over the years on the basis of inconstant conventions and variable graphic taste. Hence, the possibility to observe drawings that have been produced at different times, allows us to add a small piece of information to the history of representation.

\section{PRESERVATION IN USE}

Since we have discussed the reasons to preserve geometric surveys of the past, we now proceed discussing on how to combine the issue of keeping them as an archival documentation and as a practical resource in use. For this second purpose, past surveys need to be easily reachable and possibly available to a large span of stakeholders.

During the 1980s, the rise of the automated design software brought a change in the field of architecture and civil engineering and, therefore, in the geometric survey. Although digital formats quickly outmoded paper, the shift was not sudden, as digital and paper format drawings have been kept in use together. Nevertheless, a wide patrimony of traditional surveys begun being collected in libraries and archives. Following this trend, the International Council on Archives (ICA) (3) has focused its attention on the importance of architectural records as "chronicles of mankind's built environment". Acknowledging the many practical issues related to these fragile, often over-sized materials and their preservation, ICA established a Committee on Architectural Records, with the purpose of planning a better management of this type of documentation. This resulted into the

documents and from the online digital archive «Gli anni della Cupola 1417-1436». 
writing of a set of specific guidelines (International Council on Archives, 2000) for the conservation of materials produced in the field of architecture. It can be considered the very first attempt to a systematic approach to the various issues related to the process of cataloguing and conservation of architectural funds. It deals with a number of topics following a preventive conservation approach, e.g. the characterization of the different materials to preserve, their organization within an archive, the rules for their physical conservation.

Beside granting the preservation, a second task consist in how to foresee a possible active use for past drawings, thus not limiting the relevance of paper surveys to their documental value. Indeed, the conservation-in-use of existing surveys is rather complex, and it implies their conversion to digital for conservation reasons i.e. to have a digital copy. This process leads to the possibility to analytically discuss the level of accuracy of past surveys and to compare them to the outcomes we may obtain today, thanks to the most advanced tools. A few researches have already pointed out some outcomes from this comparison, regarding both single buildings and historical cartography. A very recent research provides us with a precise comparison between an historical / paper format survey and a contemporary / digital format survey of the well-known Tempietto di San Pietro in Montorio (Roma). The building was surveyed and drawn by Paul Letarouilly in the 19th century and re-surveyed by means of laser scanning by Fortunato and others (Fortunato, 2010a).

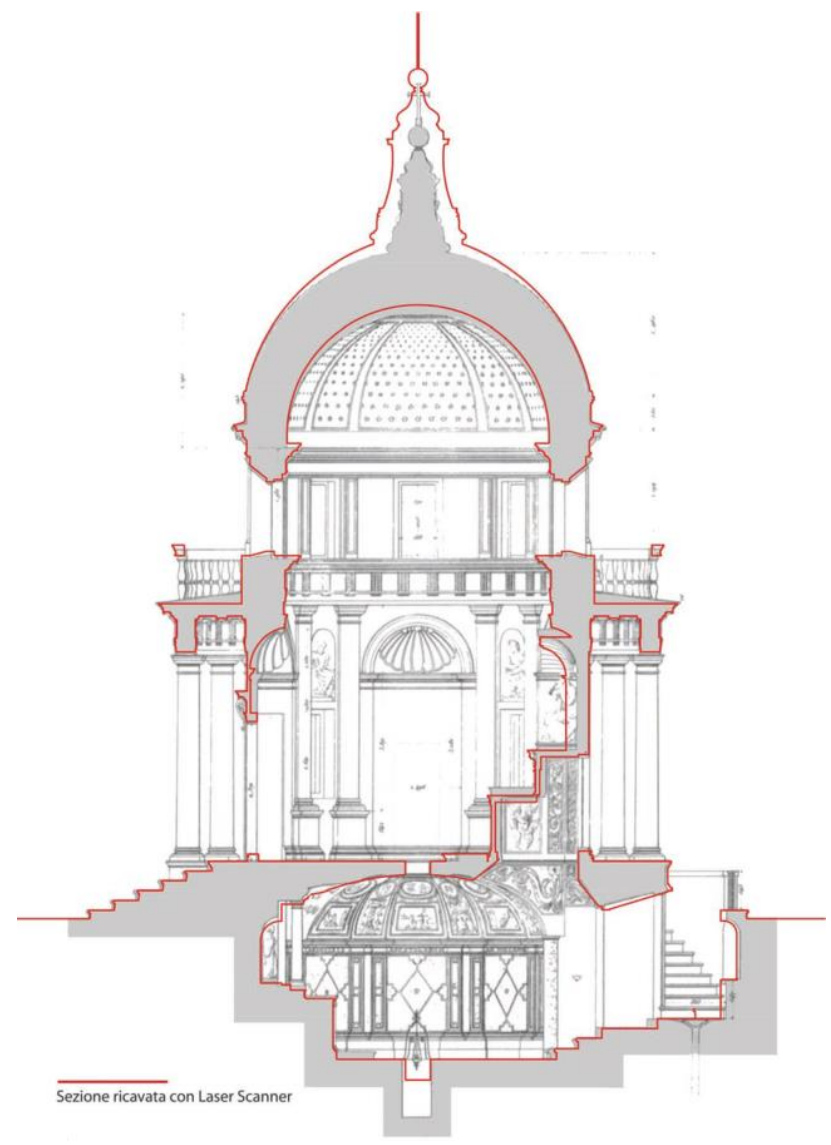

Figure 2. Comparison between Letarouilly's drawing and a recent laser scanner survey (Fortunato, 2010)

The overlapping of the two representations has proved quite precise, except for a few discrepancies, mostly regarding the least accessible areas of the building. In particular, the small lantern located on the top of the dome was hardly measurable with the instrumentation at disposal of Letarouilly, while it was entirely detected thanks to the contemporary techniques.

This analysis has been further implemented within a $\mathrm{PhD}$ thesis which has compared the same laser scanner survey with other historic drawings by the hand of Sebastiano Serlio, Andrea Palladio and Giuseppe Marini (Fabbri, 2013). The results are not homogeneous, as several different errors can be found in these representations, however Letarouilly's survey classifies as the most accurate among the historic drawings.

It is interesting to note that a previous attempt to assess the reliability of Letarouilly's work was made in the '90s. In this case the survey was mainly conducted with the aid of traditional technology, but, nonetheless, the outcome was not entirely consistent with the nineteenth-century drawings (Schuller, 2002). A similar analysis has been carried out on the Baptistery of Parma (Zerbi et al., 2019), where the ultimate laser scanner survey was compared with the 19th century's drawings by G. Bertoluzzi, until recently considered the most reliable survey of the building. The outcome of this attempt has highlighted several incongruities consisting in different rotation angles, translations, as well as in an overall enlargement of the external walls. It is surprising to learn that surveys executed centuries ago, with the most basic tools are not always so distant in terms of accuracy from the ones that are carried out today through advanced technologies. Of course this is extremely variable and it is strictly connected to the attention paid by the operator, as well as to the precision of the instrumentation. Also, it is important to consider the fact that the level of precision of each survey has been calibrated to its own purposes, today as in the past, and it is not appropriate to take its reliability for granted without verifying whether there is effective consistency between the representation and the real object. While comparing traditional and contemporary survey, it is more reasonable to discuss the issue of accuracy in terms of consistency and effectiveness, than simply as of level of detail.

A further attempt at preservation-in-use was carried out on historical cartography (Cuca et al. 2011a). Setting the objective of increasing the use and the accessibility of historical documentation concerning the planning within anthropized contexts, the study aims at collecting and systematically digitizing a series of maps drawn up over time.

The comparison between these drawings would allow to pursue two different goals: on one hand the monitoring of the water regime and its changes throughout the years, resulting in the possibility to assess the hydro-geological risk. On the other hand the chance to plan interventions that are more cautious and attentive towards the historical features of places. In order to share the collected information, all of the maps have been uploaded on the internet and are now available through an online platform.

If previous examples have proved the usefulness of the comparison between surveys conducted in different times, other researches have focused their attention on how to grant openaccess to these documents.

Following this experience, a new project has been developing (Brumana et al, 2018a). The starting point of the study is the awareness of the fact that, most of the times, informational documentation collected during academic or professional studies risks being dispersed. In fact, so far, there are no suitable platforms designed to gather such data. This aspect represents a clear downside, as the impossibility to give new visibility to the collected documentation implies its unavoidable return to a state of oblivion. The proposal of the study is hence to establish a "Virtual Hub" operating on international level to collect and share information and documentation by means of HBIM informative models. In this case, the research focuses on the constructive techniques employed to build vaults and domes. The goal is thus to create an inventory that can be fed and consulted 
from all over the world. Due to the heterogeneous nature of this kind of structures, the research criteria will be based on semantic, geographic and temporal sub-settings.

On the European panorama, an experiment worth mentioning also because of its precociousness - is the one started several years ago in Netherlands by the Netherlands Architecture Institute (NAI) (4). This innovative institution has created a completely accessible online database, containing various types of architectural documentation materials - both digitized and digital native - in order to make them available via the internet. The project is still ongoing, and it allows to visualize and download the digitized copies of most of the documents stored within the archive.

This is the desirable future of all historical surveys, as it would guarantee their maximum exploitation as operative tools to address interventions on built heritage. Nowadays, preparatory historical analysis are as eagerly suggested as they are difficult to conduct, and the reason for this is precisely the difficulty of their retrieval. The digitization process and the creation of online database, partly begun in the past years, would grant easier access to historical sources leading to a double benefit: a better conservation of the documentation which, not being manually consulted anymore would avoid several risks, and, indeed, the possibility for professionals to gain total access to archival information, with possible positive consequences on heritage management.

The abovementioned pioneering initiatives still represent isolated events, as the optimal solution to the "conservation-in-use" of geometric surveys still needs to be developed and implemented. One of the main difficulties that still needs to be overcome regards the matter of quick obsolescence of technological objects, which not only concerns advanced survey techniques, but the whole digital world. What is even worse, is that obsolescence is a risk that regards paper format surveys of the past, but also - and even more - digital surveys of the recent past. In fact, software and format incompatibilities could rapidly prevent the usage of drawings that are no more than few years old (Audisio, 2011a).

In addition, the growing accuracy of new survey instruments, by decreasing attractiveness of previous products, contributes to their premature obsolescence. Paradoxically, the quicker innovative drawings replace old ones making them obsolete, and the faster automatic design software lose the possibility of reading information contained in the previous drawings, the more the issue of preservation of previous surveys becomes current.

\section{CONCLUSIONS}

If the relevance of geometrical surveys in the field of preservation of built heritage is by now certain, largely acknowledged and exercised, at the moment there is no likewise sensitivity towards the conservation of the products of these same surveys. Yet this document, just as the monument it represents, configures as memory of both a specific state of conservation, and the historical (or present) technique that has shaped it. Furthermore, according to the principles of the Venice Charter (1964), each intervention on historical buildings should be largely documented.

Although developing new and more performing technologies is a central goal in the geomatic field, we thus need to sustain a research concerning the conservation in use of old, and even not so old, geometric surveys for heritage preservation.

However, given how quickly current survey techniques produce new results, it is clear that this field of activity will gain increasing relevance in the near future. In fact, as we are accustomed to interpret the buildings of the past as a stratification of information, similarly in the near future we will face the theme of how to decode the stratification of information due to the different surveys carried out at different times on the same building or site.

\section{REFERENCES}

Archivio di Stato di Milano (edited by), 1984. L'immagine interessata. Territorio e cartografia in Lombardia tra 500 e 800, New Press, Como.

Artt. 2,10,11 del D.Lgs n. 42 del 22/01/2004 cd Codice dei Beni Culturali e del Paesaggio.

Audisio L., 2011a. La catalogazione del disegno di architettura nell'era digitale, DisegnareCon, dicembre 2011, 116-123.

Cuca B., Brumana R., Scaioni M., Oreni D., 2011a. Spatial Data Management of Temporal Map Series for Cultural and Environmental Heritage, in International Journal of Spatial Data Infrastructures Research, Vol. 6, 1-31.

Denker A., 2017a. Rebuilding Palmyra virtually: recreation of its former glory in digital space, in Virtual Archaeology Review, 8(17), 20-30.

Docci M., 2011. La ricerca scientifica nel settore del rilevamento architettonico e urbano tra passato, presente e futuro, in E. Chiavoni, M. Filippa (edited by), Metodologie integrate per il rilievo, il disegno, la modellazione dell'architettura e della città, Gangemi, Roma.

Docci M., Gaiani M., Migliari R., 2001. Una nuova cultura per il rilevamento, Disegnare Idee Immagini, 2001, 37-46.

Fabbri L., 2013. Il Tempietto di San Pietro in Montorio attraverso metodologie di rilevamento avanzato per lo studio della forma, della materia e della struttura dell'architettura, Tesi di Dottorato della Scuola Nazionale di Dottorato in Scienze della Rappresentazione del Rilievo, Dipartimento di Storia, Disegno e Restauro dell'Architettura, Università degli Studi di Roma "Sapienza", Roma.

Fortunato G., 2010a. The role of architectural representation for the analysis of the built. The 3D survey of San Pietro in Montorio's temple in Rome, APEGA 2010. X Congreso Internacional de Expresión Gráfica aplicada a la Edificación, Editorial Marfil, Alcoy.

Ghiretti A., Ottoni F., 2009. Analisi grafica e metrologia, in Giandebiaggi P., Mambriani C., Ottoni F. (edited by), 2009. Santa Maria del Quartiere in Parma: storia, rilievo e stabilità di una fabbrica farnesiana, Grafiche Step, Parma.

Grün A., Remondino F., Zhang L., 2004a. Photogrammetric reconstruction of the Great Buddha of Bamiyan, Afghanistan, The Photogrammetric Record, 19(107), 177-199.

Guasti C., 1857. La Cupola di Santa Maria del Fiore illustrata con i documenti dell'Archivio dell'Opera secolare, Barbèra, Bianchi e Comp, Firenze.

(4) Since 2013 the Netherlands Architecture Institute has been absorbed by the Het Nieuwe Institut. 
International council on archives, Section on Architectural Records, 2000. A guide to the archival care of architectural records. $19^{\text {th }}-20^{\text {th }}$ centuries, ICA, Paris.

Leoni G., 1742. The Preface to the reader, The architecture of $A$. Palladio; Book the Third, Printed for A. ward, London, 75-76.

Marabotto M.P., 2010. L'arte del descrivere. Disegni ed incisioni nel Theatrum Statuum Sabaudiae Ducis, Tesi di Dottorato in Teoria e Storia della Rappresentazione, Facoltà di Architettura di Siracusa, Università di Catania.

Musso S., 2017a. Rilevare/Restaurare: una diade inscindibile, Ananke, novembre 2017, 24-29.

Schmidt H., 2002. Building research from past to present. The development of methods in Germany since the $19^{\text {th }}$ century, in De Jonge K., Van Balen K. (edited by), 2002. Preparatory Architectural Investigation in the Restoration of Historical Buildings, Leuven University Press, Leuven, 15-29.
Schuller M., 2002. The application of bauforschung methodology and presentation, in De Jonge K., Van Balen K. (edited by), 2002. Preparatory Architectural Investigation in the Restoration of Historical Buildings, Leuven University Press, Leuven, 31-47.

Senatore L.J., 2011. La scala del modello digitale, in E. Chiavoni, M. Filippa (edited by), Metodologie integrate per il rilievo, il disegno, la modellazione dell'architettura e della città, Gangemi, Roma.

Torsello B.P., 1988. La materia del restauro, Marsilio, Venezia, 128.

Zerbi A., Mikolajewska S., 2019a. From survey to model, and return. The case of the Parma Baptistery, The International Archives of Photogrammetry, Remote Sensing and Spatial Information Sciences, Volume XLII-2/W9. 